\title{
Retraction Note: Crystal's anisotropic properties and tensor representation: a discussion
}

The Publishers

EDP Sciences, Società Italiana di Fisica and Springer-Verlag

Original article: Eur. Phys. J. Plus (2011) 126: 128, DOI: 10.1140/epjp/i2011-11128-3

Received: 6 March 2013

Published online: 27 March 2013 - C Società Italiana di Fisica / Springer-Verlag 2013

It has come to the attention of the European Physical Journal Plus that the article "Crystal's anisotropic properties and tensor representation: a discussion" by E. Talebian and M. Talebian, Eur. Phys. J. Plus 126, 128 (2011), should not have been published because it reproduces some work already published in:

- A.R. Verma, O.N. Srivastava, Crystallography Applied To Solid State Physics (New Age International, 1991) Chapt. 7;

- G. Bassani, G. Liedl, P. Wyder (Editors), Encyclopedia of Condensed Matter Physics (Elsevier, 2005) pp. 300-309;

- E. Fjær, R.M. Holt, A.M. Raaen, P. Risnes, P. Horsrud, Petroleum Related Rock Mechanics, second edition (Elsevier, 2008).

Consequently, this paper has been retracted by the European Physical Journal Plus and should not be cited or referred to in the future. 